\title{
Normal joint mobility in mitral valve prolapse
}

\author{
J. S. MARKS, J. SHARP, S. G. BREAR, AND J. D. EDW ARDS \\ From the University Hospital of South Manchester and Devonshire Royal Hospital, Buxton
}

SUMmaRY Thirty-seven adults (19 male, 18 female) with mitral valve prolapse (MVP) were examined for evidence of joint hypermobility scored on a 0-9 scale. None of the patients had hypermobility scores exceeding 3, and comparison with 37 healthy age and sex matched controls recruited from hospital staff failed to show an increased prevalence of hypermobility in MVP. There was no evidence that the MVP syndrome is a forme fruste of a heritable disorder of connective tissue.

The mitral valve prolapse syndrome (MVP) is recognised clinically by the presence of a mid-systolic click and late systolic murmur and echocardiographic evidence of posterior mitral leaflet prolapse into the left atrium. ${ }^{1}$ The accumulation of procollagen in floppy mitral valves has been reported, ${ }^{2}$ as has an absence of type III collagen, ${ }^{3}$ and both raise the question of whether the abnormality of the mitral valve is an isolated lesion or part of a more generalised disturbance. The association of MVP with Marfan's syndrome, ${ }^{4}$ the Ehlers-Danlos syndrome, ${ }^{5}$ and the straight-back syndrome ${ }^{6}$ suggests that MVP should be regarded as part of a heritable disorder of connective tissue.

Mitral valve prolapse is of interest to rheumatologists because of its reported association with floppy joints. ${ }^{7}$ One study ${ }^{8}$ has shown an increased incidence of MVP in patients with the hypermobile joint syndrome, though others ${ }^{9}$ have failed to confirm this association.

We have therefore examined patients with MVP for evidence of abnormal joint laxity.

\section{Patients and methods}

Thirty-seven patients (19 male, 18 female) with MVP confirmed by echocardiograph were assessed for joint hypermobility scored on a $0-9$ scale by the criteria of Beighton et al., ${ }^{10}$ in which one point is allotted for the ability to perform each of the following tests: (a) passive dorsiflexion of the metacarpophalangeal joint of each fifth finger beyond $90^{\circ} ;(b)$ passive opposition of each thumb to the flexor aspects of the forearms; $(c)$ hyperextension of each

Accepted for publication 20 January 1982.

Correspondence to $\mathrm{Dr}$ J. S. Marks, Stepping Hill Hospital, Stockport SK2 7JE. elbow beyond $10^{\circ} ;(d)$ hyperextension of each knee beyond $10^{\circ} ;(e)$ forward flexion of the trunk with knees extended so that the palms of the hands rest on the floor.

A comparison was made with 37 age and sex matched healthy controls recruited from the following staff of the Devonshire Royal Hospital: medical 8 , paramedical 9 , secretarial 5 , domestic 6 , and manual 9. Individuals from both groups were examined alternatively by JS or JSM, with abnormal findings being confirmed by both observers.

\section{Results}

The thirty-seven patients with MVP had presented with cardiac symptoms - usually chest pain or palpitations-or had been referred to a cardiology unit because of a heart murmur. None of the patients had evidence of an underlying heritable connective tissue disease based on the subjective assessment of skin elasticity, palate height, body habitus, easy bruising, or scleral blueness. Patients with inflammatory joint disease were excluded. The patients were matched for age and sex with controls recruited from hospital staff (Table 1).

There was no evidence that the joints of patients with MVP were abnormally mobile when compared with those of a control group (Table 2). None of the

Table 1 Age and sex characteristics of MVP and control groups

\begin{tabular}{|c|c|c|}
\hline Age (years) & No. of patients $M V P$ & Controls \\
\hline $15-25$ & $4 \mathrm{~F}$ & $4 \mathrm{~F}$ \\
\hline $26-40$ & $5 M$ & $5 F$ \\
\hline $41-65$ & $9 \mathrm{~F} \quad 14 \mathrm{M}$ & $9 \mathrm{~F} \quad 14 \mathrm{M}$ \\
\hline
\end{tabular}

$\mathrm{F}=$ female. $\mathrm{M}=$ male. 
Table 2 Hypermobility scores in MVP and controls

\begin{tabular}{lcc}
\hline Hypermobility score & $M V P$ & Controls \\
\hline 0 & 28 & 21 \\
1 & 2 & 6 \\
2 & 4 & 6 \\
3 & 3 & 2 \\
4 & 0 & 2 \\
$5-9$ & 0 & 0 \\
\hline
\end{tabular}

Table 3 Pattern of joint hypermobility

\begin{tabular}{llc}
\hline Joint group & $M V P$ & Controls \\
\hline Extension MCP 90 & 4 & 1 \\
Thumb to forearm & 5 & 17 \\
Elbow extension $10^{\circ}$ & 2 & 5 \\
Knee extension $10^{\circ}$ & 4 & 0 \\
Palm to floor & 4 & 9 \\
\hline
\end{tabular}

patients with MVP had a hypermobility score in excess of 3.

The pattern of individual joint mobility has been compared in both groups (Table 3). Joint hypermobility in the MVP patients is seen to be fairly evenly distributed across the 5 joint groups assessed, while the controls showed preferential hypermobility of thumb movements and spinal flexion.

\section{Discussion}

We have been unable to confirm an earlier study which showed a relationship between MVP and joint hypermobility. Our patients initially presented to a general medical or cardiology clinic. We tried to avoid any bias by excluding patients who had been seen previously in a rheumatology clinic.

In common with earlier studies we have assessed joint hypermobility by using the method of Carter and Wilkinson ${ }^{11}$ as modified by Beighton et al. ${ }^{10}$ The absolute score of hypermobility was comparable in the MVP and control groups, but this failed to take account of differences in the distribution of abnormally mobile joints (Table 3 ), and a system of scoring which did not limit itself to 5 joint groups might have shown some differences between the MVP and control groups.

Our study has shown that the patients with MVP do not have generalised joint laxity and we have not found any evidence to support the view that MVP should be regarded as a forme fruste of a heritable disorder of connective tissue.

We are grateful to Dr D. C. Beton, who carried out the echocardiography.

\section{References}

1 Barlow J B, Pocock W A. Mitral valve prolapse, the specific billowing mitral leaflet syndrome, or an insignificant nonejection systolic click. Am Heart J 1979; 97: 277-83.

2 Bonella D, Porter D J, Davies M J. Accumulation of procollagen in human floppy mitral valves. Lancet 1980 ; i: 880-1.

3 Hamer D V, Leier C V, Baba N, Vasco J S, Wooley CF, Pinnell S R. Altered collagen composition in a prolapsing mitral valve with ruptured chordae tendineae. Am J Med 1979; 67: 862-6.

4 Brown O R, Demots H, Kloster F E, Roberts A, Menashe V D, Beals R K. Aortic root dilatation and mitral valve prolapse in Marfan's syndrome. Circulation 1975; 52: 651-7.

5 Brandt K D, Sumner R D, Ryan T J, Cohen A S. Herniation of mitral leaflets in the Ehlers-Danlos syndrome. Am J Cardiol 1975; 36: 524-657.

6 Daview M K, Mackintosh P, Cayton R M, Page A J F, Shiu M F, Littler W A. The straight-back syndrome. $Q J$ Med 1980; 49: 443-60.

7 Pitcher D, Graham R. Joint Mobility in mitral valve prolapse. Paper read to combined meeting of Heberden Society, BARR, and RSM (Nottingham), 1980.

8 Grahame R, Edwards J H, Pitcher D, Gabell R A, Harvey W. A clinical and echocardiographic study of patients with hypermobility syndrome. Ann Rheum Dis 1981; 40: 541-6.

9 Jessee E F, Owen Jr D S, Sagar K B. The benign hypermobile syndrome. Arthritis Rheum 1980; 23: 1053-6.

10 Beighton P, Soloman L, Soskolne C L. Articular mobility in an African population. Ann Rheum Dis 1973; 32: 413-8.

11 Carter C, Wilkinson J. Persistent joint laxity and congenital dislocation of the hip. J Bone Joint Surg 1964; 46B: 40-5. 